\title{
Photoluminescence of Electrodeposited ZnO Hybrid Thin Films
}

\author{
H. Iwai, ${ }^{1}$ K. Mizuta, ${ }^{1}$ A. Yamamoto, ${ }^{2}$ H. Yanagi ${ }^{2}$ and T. Yoshida ${ }^{1 *}$ \\ 1 Environmental and Renewable Energy Systems (ERES) Division, Graduate School of Engineering, \\ Gifu University, Yanagido 1-1, Gifu 501-1193 \\ Fax: 81-058-293-2593, *e-mail: yoshida@apchem.gifu-u.ac.jp \\ 2 Graduate School of Materials Science, Nara Institute of Science and Technology, \\ 8916-5 Takayama-cho, Ikoma, Nara 630-0192
}

\begin{abstract}
Photoluminescence (PL) properties have been studied for electrodeposited porous $\mathrm{ZnO}$ thin films hybridized with luminescent rare earth metal complexes and organic molecules. Nanoporous $\mathrm{ZnO}$ films were cathodically electrodeposited from the bath containing eosin Y (EY). Various bridging ligands (BLs) having carboxylic acid group as anchor was loaded to ZnO. These BLs have the moiety to coordinate to metal ions and thus can form complexes on $\mathrm{ZnO}$ surface by uptaking metal ions such as $\mathrm{Eu}^{3+}, \mathrm{Tb}^{3+}$ and $\mathrm{Al}^{3+}$. Fluorescent organic molecules having carboxylic acid group has been chosen and are also attached from their solutions. Some of the hybrid thin films with metal complexes exhibited PL, while none of organic molecules showed PL. Especially efficient were the films with Eu ${ }^{3+}$ complexes. Its PL intensity was further increased by capping $\mathrm{Eu}^{3+}$ with $\beta$-diketones. The quantum efficiency for its PL was determined as $21 \%$ when only the ligand to metal energy transfer is taken into account.

Key words: Electrodeposition, $\mathrm{ZnO}$, luminescence, lanthanide, thin films
\end{abstract}

\section{Introduction}

Semiconductor nanostructures have attracted much attention in recent years. In comparison with the bulk materials, they are to have unique properties such as the quantum size effect [1]. Among compound semiconductors, metal oxides and nitrides are especially interesting for their electronic and optoelectronic properties, finding various applications such as dye-sentitized solar cells, gas sensors, catalysts and phosphors [2-7].

Zinc oxide $(\mathrm{ZnO})$ has a large exciton binding energy $(60 \mathrm{meV})$ and a wide band gap $(3.4 \mathrm{eV})$, making its exciton stable at room temperature. Because of such properties, $\mathrm{ZnO}$ nanocrystals are suitable host materials for doping with luminescent centers such as rare earth metals [8-10]. It is well known that rare earth complexes exhibit extremely sharp visible light emission compared with fluorescent dyes and polymers [11-13]. 4f orbitals are effectively shielded from the influence of the surrounding by overlaying the $5 s$ and $5 p$ orbitals. Furthermore, the lanthanide ions can be excited via an intramolecular energy transfer from the triplet excited state of the ligands. The internal quantum efficiency of the rare earth complexes as emitter layers can theoretically be as high as $100 \%$. In organic light emitting diodes (OLEDs), such metal complexes are doped into organic semiconductors $[11,12]$. However the organic layers usually have low carrier mobility and are unstable against oxygen and moist. Hybridization of organic molecular light emitters with inorganic semiconductors with high carrier mobility and chemical stability is therefore a promising strategy. Such compounds exhibit increased thermal and emission stability in time [14].

Recently, we have shown that organic dye moleules can be hybridized with $\mathrm{ZnO}$ during its cathodic electrodeposition by simply adding water soluble dye into the deposition bath. Self assembly of $\mathrm{ZnO} /$ dye hybrid nanostructure evolves because of adsopriton of dye molecules to the growing surface of $\mathrm{ZnO}$ [15-19]. These hybrid thin films perform as efficient photoelectrodes for dye-sensitized solar cells (DSSCs). The same approach of materials synthesis has successfully been applied to preparation of hybrid thin films of $\mathrm{ZnO}$ and rare earth metal complexes, which exhibit photoluminescence (PL) in different colors, since a large amount of complexes can be attached owing to the high surface area [13].

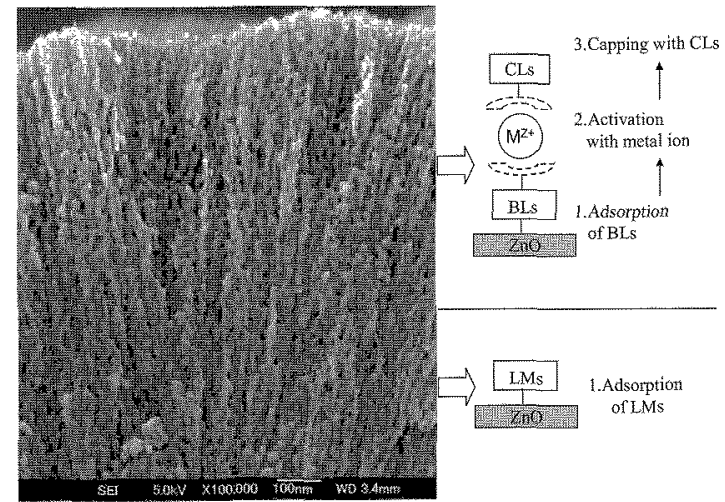

Fig.1 Cross sectional view of electrodeposited porous $\mathrm{ZnO}$ film and procedure to synthesize luminescent hybrid thin films.

The synthetic strategy of the luminescent hybrid thin film is schematically presented in Fig. 1. Porous crystalline $\mathrm{ZnO}$ is prepared by hybridization with eosinY (EY) and subsequent extraction of EY. It is soaked in solution of bridging ligands (BLs) having carboxylic acid group as anchor to $\mathrm{ZnO}$ and another 
moiety to coordinate to metal ions. The $\mathrm{ZnO}$ film modified with BLs is then soaked in the solution of central metal ions (CMs) to form complexes. The surface grafting is finally completed by capping ligands (CLs) which stabilize the complex. Alternatively, luminescent organic molecules (LMs) with anchoring group can also be attached directly to the porous $\mathrm{ZnO}$. Suitable hole conductor may finally be deposited on such layer to construct a hybrid EL devices and that is the final goal of our study.

The aim of this study is to attempt to increase the variation of luminescent hybrid by combination of various, BLs, CMs and CLs. For those with good PL properties, their PL as well as the PL excitation (PLE) spectra were measured to discuss the PL mechanism. Absolute quantum yields of PL were also determined.

\section{Experimental}

2.1 Electrodeposition of porous $\mathrm{ZnO}$ thin films

Fluorine doped $\mathrm{SnO}_{2}$ (FTO) coated glass (10 $\Omega / \square$ Asahi glass) sheets were cleaned ultrasonically in acetone, 2-propanol, soap solution, and water. They were activated in $45 \% \mathrm{HNO}_{3}$ for $2 \mathrm{~min}$ and finally rinsed with distilled water prior to the deposition.

An aqueous solution was prepared as deposition bath to contain $5 \mathrm{mM} \mathrm{ZnCl}_{2}$ (Merck) and $0.1 \mathrm{M} \mathrm{KCl}$ (Merck). Disodium salt of EY (Kanto) was added into the deposition bath at $45 \mu \mathrm{M}$ for preparing $\mathrm{ZnO} / \mathrm{EY}$ hybrid film. A three-electrode single compartment cell was used. FTO glass was used as a working electrode by applying it to a Radiometer Analytical (EDI101 and CTV101) rotating electrode system. The rotation rate was set to $500 \mathrm{rpm}$. A Zn wire $(99.9 \%)$ was used as a counter electrode. The potential was referred to an $\mathrm{Ag} / \mathrm{AgCl}$. The cell was placed in a thermostat bath maintained at $70^{\circ} \mathrm{C}$. Oxygen gas was bubbled at $100 \mathrm{ml}$ $\min ^{-1}$ for $30 \mathrm{~min}$ prior to the actual electrolysis and the same gas flow was maintained during the deposition. The electrolysis was carried out for $20 \mathrm{~min}$ potentiostatically at $-0.95 \mathrm{~V}$ (vs. $\mathrm{Ag} / \mathrm{AgCl}$ ). A Hokuto Denko HSV-100 was used for the potential control and the current monitoring. The obtained $\mathrm{ZnO} / \mathrm{EY}$ hybrid film was converted to a porous $\mathrm{ZnO}$ by soaking it into a dilute $\mathrm{KOH}$ solution at $\mathrm{pH} 10.5$ to extract $\mathrm{EY}$.

2.2 Grafting of luminescent complexes and molecules

As shown in Fig. 1, the porous $\mathrm{ZnO}$ surface was modified by subsequently soaking the film into ethanolic solutions containing BLs, CMs and CLs at a few hundreds of $\mu \mathrm{M}$, then refluxing the solutions for $1 \mathrm{~h}$. Various BLs were tested but results with $2,2^{2}$-bipyridine dicarboxylic acid (dcbpy) and 8-hydroxyquinoline 5-sulfonic acid (hqs) (Fig. 2) are only reported here. The CMs such as $\mathrm{Eu}^{3+}, \mathrm{Tb}^{3+}$ and $\mathrm{Al}^{3+}$ were used as chlorides. The CLs (CL1-4) were $\beta$-diketones as shown in Fig. 2. ZnO surface was also furnished with LMs such as eosinY (LM1), 1-pyrene carboxylic acid (LM2) and Salicylic acid sodium salt (LM3) by refluxing the film in their $0.2 \mathrm{mM}$ ethanolic solutions.

\subsection{Photoluminescence measurements}

The PL and PLE spectra of the solid samples were measured on a Hitachi F-4500 spectrofluorimeter at room temperature by placing the film at $45^{\circ}$ angle with respect to the excitation and the monitoring beams. The PL, PLE and absorption spectra were also measured for solutions of the metal complexes prepared by mixing BLs, CMs and CLs at stoichiometric ratio for known form of the complexes. Absolute PL quantum yield was measured on a Hamamatsu Photonics C9920-02 system equipped with an integration sphere to place the film sample and counting the number of photons detected by a diode array photometer.

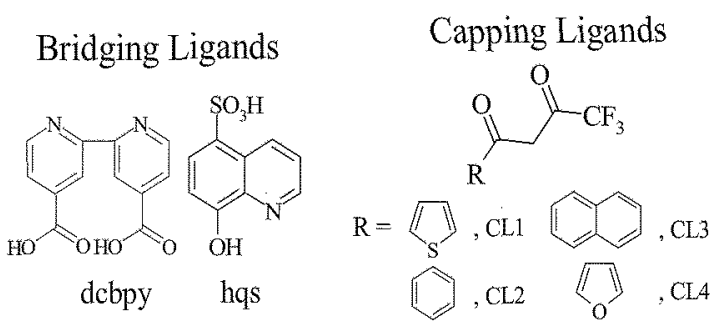

Fig:2 Molecular structures of BLs and CLs

\section{Results and Discussions}

About 50 film samples were prepared by combination of various BLs, CMs and CLs. Many of them were successfully attached to the $\mathrm{ZnO}$ surface and exhibited PL properties with different intensities, although formation of complexes were not achieved when CMs such as $\mathrm{Pr}^{3+}, \mathrm{Sm}^{3+}, \mathrm{Dy}^{3+}, \mathrm{Ho}^{3+}, \mathrm{Tm}^{3+}$ and $\mathrm{Ir}^{3+}$ were chosen. Among the samples, those with $\mathrm{Eu}^{3+}$ and $\mathrm{Tb}^{3+}$ attached through dcbpy as $\mathrm{BL}$ and $\mathrm{Al}^{3+}$ complex with hqs exhibited relatively intense PLs in visible region as shown in Fig. 3. The $\mathrm{ZnO} / \mathrm{dcbpy}-\mathrm{Eu}^{3+}$ film emits red light with several sharp peaks, characteristic of intra- $4 \mathrm{f}$ transitions of $\mathrm{Eu}^{3+}$ attributed to ${ }^{5} \mathrm{D}_{0} \rightarrow{ }^{7} \mathrm{~F}_{1},{ }^{5} \mathrm{D}_{0} \rightarrow{ }^{7} \mathrm{~F}_{2}$ ${ }^{5} \mathrm{D}_{0} \rightarrow{ }^{7} \mathrm{~F}_{3}$ and ${ }^{5} \mathrm{D}_{0} \rightarrow{ }^{7} \mathrm{~F}_{4}$ at $590,612,650$ and $700 \mathrm{~nm}$, respectively. The $\mathrm{ZnO} /$ dcbpy- $\mathrm{Tb}^{3+}$ film exhibits green emissions due to intra-4f transitions of $\mathrm{Tb}^{3+}$ assigned to ${ }^{5} \mathrm{D}_{4} \rightarrow{ }^{7} \mathrm{~F}_{\mathrm{j}}(\mathrm{j}=6,5,4,3)$ at $490,543,587$ and $622 \mathrm{~nm}$, respectively. In contrast to these lanthanoid complexes, the $\mathrm{ZnO} / \mathrm{hqs}-\mathrm{Al}^{3+}$ film exhibits a broad emission centered at $515 \mathrm{~nm}$, similarly to the well known $\mathrm{Al}^{3+}$ 8-hydroxyquinoline complex $\left(\mathrm{Alq}_{3}\right)$ [20-22]. The broad character of $\mathrm{PL}$ arises from that the electronic transition of $\mathrm{Alq}_{3}$ is localized in the quinolate ligands, in contrast to the rare earth metal complexes.

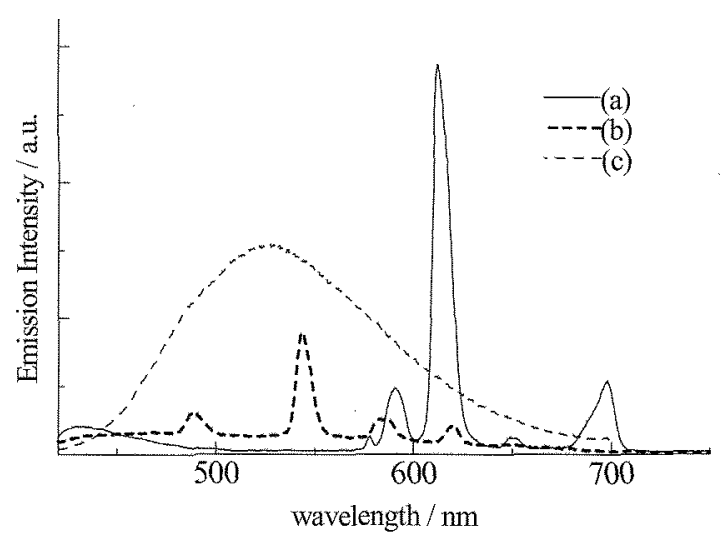

Fig.3 PL spectra of $\mathrm{ZnO}$ films hybridized with luminescent complexes excited at $315 \mathrm{~nm}$. (a) $\mathrm{ZnO}$ / dcbpy- $\mathrm{Eu}^{3+*}$, (b) $\mathrm{ZnO} / \mathrm{dcbpy}-\mathrm{Tb}^{3+}$ and (c) $\mathrm{ZnO} /$ hqs- $\mathrm{Al}^{3+}$. 
All of LMs could also be attached to $\mathrm{ZnO}$ owing to the presence of carboxylic acid anchoring group, as confirmed by UV-Vis absorption spectroscopy. These LMs in solutions emit intense PLs in the visible, but they were completely quenched when hybridized with ZnO. Fast and efficient electron injection from photoexcited state of fluorescent dye molecules to the conduction band of $\mathrm{ZnO}$ is a key process in DSSCs [23]. It is likely that such electron transfer occurs for the LMs tested here, because the lowest unoccupied molecular orbitals (LUMOs) of LMs are located way above the conduction band (CB) of $\mathrm{ZnO}$. From such thermodynamic arguments, however, the LUMOs of BLs are also above the $\mathrm{CB}$ of $\mathrm{ZnO}$. It is understood that intramolecular energy transfer from BLs to CMs prevails to the quenching of excited state of BLs. The visible PL is therefore specific for the hybrid films with such metal complexes.

The PL intensity the hybrid film with $\mathrm{Eu}^{3+}$ complexes was further increased by capping the complex with CLs. The CLs are expected to coordinate to $\mathrm{Eu}^{3+}$ to stabilize the complex. On the other hand, no such enhancement was observed when $\mathrm{Tb}^{3+}$ samples were treated with CLs.

The PLE spectra of the film samples are compared to the absorption spectra of BL and CL in Fig. 4. The PLE of $\mathrm{ZnO}$ shows several features below ca. $250 \mathrm{~nm}$ originating from transitions in $\mathrm{ZnO}$. These features are also recognized in the hybrid film samples with the higher intensities, suggesting energy transfer from $\mathrm{ZnO}$ to the complex. However, the $\mathrm{PL}$ of $\mathrm{ZnO} / \mathrm{dcbpy}-\mathrm{Eu}^{3+}$ system seems to reflect mainly the broad peak at around $310 \mathrm{~nm}$. The shape of this peak resembles with that of the absorption of dcbpy appearing at somewhat shorter wavelength of $297 \mathrm{~nm}$. It is reasonably understood that the PL originates by photoexcitation of the $\mathrm{ZnO}$-bound dcbpy and energy transfer to $\mathrm{Eu}^{3+}$. Similar features were observed in the PLE spectrum of $\mathrm{ZnO} / \mathrm{dcbpy}-\mathrm{Tb}^{3+}$ indicating energy transfer from dcbpy to $\mathrm{Tb}^{3+}$ as the mechanism of PL.

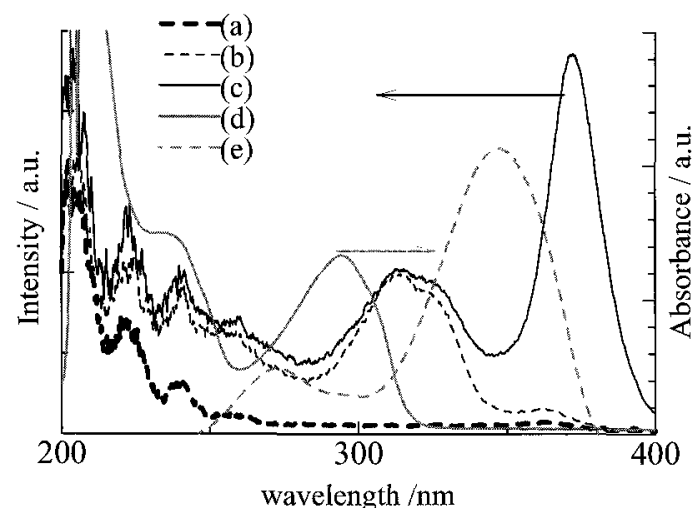

Fig.4 Comparison of PLE and absorption spectra; PLE of (a) $\mathrm{ZnO}$, (b) $\mathrm{ZnO} / \mathrm{dcbpy}-\mathrm{Eu}^{3+}$ and (c) $\mathrm{ZnO} /$ dcbpy-Eu ${ }^{3+}-\mathrm{CL} 1$ with monitoring emission wavelength of $612 \mathrm{~nm}$. Absorption spectra of ethanolic solutions of (d) debpy (d) and (e) CL1.

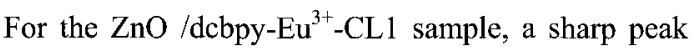
appears at $372 \mathrm{~nm}$. The absorption spectrum of CL1 shows a peak at $347 \mathrm{~nm}$, although much broader in shape. When the $\mathrm{ZnO} / \mathrm{dcbpy}-\mathrm{Eu}^{3+}$ sample was treated with CL2, 3 and 4, similar peaks appeared in their PLE spectra at 366,374 , and $368 \mathrm{~nm}$, respectively. All of these peaks are red-shifted by ca. $30 \mathrm{~nm}$ from those of the absorption of respective CL molecules in solution. These new peaks therefore seem to arise from the CLs coordinating to the Eu complexes bound to $\mathrm{ZnO}$. It has been elucidated that the PL of the Eu complex bound to $\mathrm{ZnO}$ mainly occurs via energy transfer from $\mathrm{BL}$ and $\mathrm{CL}$, although contribution of energy transfer from $\mathrm{ZnO}$ cannot be completely ruled out.

The PLE spectrum of $\mathrm{ZnO} / \mathrm{hqs}-\mathrm{Al}^{3+}$ sample shows totally different features from those with the lanthanoid complexes. The PLE spectrum of the film sample is compared with the absorption spectra of the solutions of hqs and $\mathrm{Al}(\mathrm{hqs})_{3}$ complex in Fig. 5. The hqs molecule possesses a sharp absorption peak at $240 \mathrm{~nm}$ and a broad one at $310 \mathrm{~nm}$. When it is complexed with $\mathrm{Al}^{3+}$, they are red-shifted to $255 \mathrm{~nm}$ and $360 \mathrm{~nm}$, respectively. These characters are similar to those of $\mathrm{Alq}_{3}$ complex in DMF solution [20-22]. The PLE spectrum of the film sample monitored for PL at $515 \mathrm{~nm}$ shows two peaks related to photoexcitation of the surface complex. The relatively sharp peak is further shifted to $365 \mathrm{~nm}$, while the broad one remains at the same position. It should be noted that the proportion of these two peaks totally differ from that of the molecular absorption. It is also noticed that the intensity of the PLE spectrum around $280 \mathrm{~nm}$, where a valley is created for the absorption of the complex, remains rather high. These features suggest contribution of $\mathrm{ZnO}$ to the PL by energy transfer to the complex.

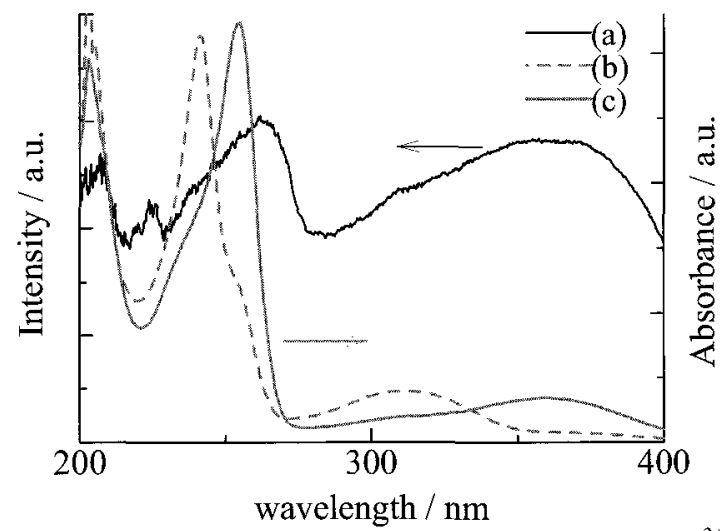

Fig.5 Comparison of (a) PLE spectrum of $\mathrm{ZnO} / \mathrm{hqs}-\mathrm{Al}^{3+}$ hybrid thin film with absorption spectra of solutions containing (b) $0.3 \mathrm{mM}$ hqs and (c) $0.3 \mathrm{mM}$ hqs, $0.1 \mathrm{mM}$ $\mathrm{Al}^{3+}$.

We have attempted to determine quantum efficiencies of PL of the hybrid thin films. The basis of the measurement depends on whether to consider the contribution of $\mathrm{ZnO}$ or not. As Case 1, light absorption only by the surface bound complexes was estimated by subtracting the light extinction by porous $\mathrm{ZnO}$ thin film without the complex from that of the hybrid thin film, assuming only the PL localized in the molecule. Case 2 takes both the molecular localized and $\mathrm{ZnO} /$ molecular cooperative processes into account, so that the efficiency is calculated from the total absorption of the film sample. Although precise evaluation of the light extinction by the molecule is difficult, because that by $\mathrm{ZnO}$ slightly differ from sample to sample, rather high quantum yields of 9.9 and $21.2 \%$ were determined in Case 1 for 
dcbpy-Eu ${ }^{3+}$ complex bound to $\mathrm{ZnO}$ excited at 310 and $370 \mathrm{~nm}$, respectively (Table 1 ). These results suggest more efficient energy transfer from dcbpy than CL1. PL measurements at $20 \mathrm{~K}$ and room temperature indicated that this sample retains PL intensity at room temperature being about half of that at $20 \mathrm{~K}$, suggesting that non radiative decay of the excited state is effectively suppressed in the hybrid film [24]. For Case 2, however, these values drop to 1.1 and $0.7 \%$, respectively, suggesting rather inefficient or no energy transfer from $\mathrm{ZnO}$ that then only filters UV light to be absorbed by the complex.

For the $\mathrm{ZnO} / \mathrm{hqs}^{-} \mathrm{Al}^{3+}$ film, quantum yields were determined only for Case 2 as 4.5 and $9.6 \%$ for excitation at 400 and $355 \mathrm{~nm}$, respectively. Because light absorption by $\mathrm{ZnO}$ at $400 \mathrm{~nm}$ is almost zero, the former can therefore be considered as reflecting the molecular localized PL, namely, the energy transfer from hqs. On the other hand, the latter originates from light absorption both by hqs and $\mathrm{ZnO}$. The higher efficiency at $355 \mathrm{~nm}$ therefore indicates rather efficient energy transfer from $\mathrm{ZnO}$ to the hqs- $\mathrm{Al}^{3+}$ complex. In fact, a constant quantum efficiency independent on the excitation wavelength was found for the Al(hqs) complex solution. The concerted action between $\mathrm{ZnO}$ and hqs- $\mathrm{Al}^{3+}$ complex to generate $\mathrm{PL}$ is a unique function of the $\mathrm{ZnO} / \mathrm{hqs}_{\mathrm{s}} \mathrm{Al} \mathrm{3}^{3+}$ hybrid thin film. Such a process may become operative because of the ligand localized PL mechanism of the hqs- $\mathrm{Al}^{3+}$ complex.

Table I. Quantum yields for PL of the hybrid films.

\begin{tabular}{|c|c|c|c|}
\hline sample & $\begin{array}{c}\text { excitation } \\
\text { wavelength } \\
(\mathrm{nm})\end{array}$ & $\begin{array}{c}\text { Quantum Yield } \\
(\%) \\
\text { Case } 1\end{array}$ & $\begin{array}{c}\text { Quantum Yield } \\
(\%) \\
\text { Case } 2 \\
\end{array}$ \\
\hline \multirow{2}{*}{$\begin{array}{l}\mathrm{ZnO} / \mathrm{dcbpy} \\
-\mathrm{Eu}^{3+}-\mathrm{CL} 1\end{array}$} & 310 & 21.2 & 0.7 \\
\hline & 370 & 9.9 & 1.1 \\
\hline \multirow{2}{*}{$\begin{array}{c}\mathrm{ZnO} / \mathrm{hqs}- \\
\mathrm{Al}^{3+}\end{array}$} & 355 & - & 9.6 \\
\hline & 400 & - & 4.5 \\
\hline
\end{tabular}

4. Conclusions

$\mathrm{ZnO}$-based visible luminescent hybrid thin films were successfully obtained by electrodeposition of porous $\mathrm{ZnO}$ and post chemical treatments to attach luminescent molecules. While PL of fluorescent organic molecules was completely quenched, those with metal complexes were found to emit PL. The strategy to build up complexes by subsequent attachment of BLs, CMs and CLs successfully worked out. Especially efficient was the system combining $\mathrm{Eu}^{3+}$ complexes with a quantumn efficiency exceeding $20 \%$. The attachment of $\mathrm{CL}$ to $\mathrm{Eu}^{3+}$ complex enhanced PL intensity. While molecular localized PL is the main mechanism for the $\mathrm{Eu}^{3+}$ system, cooperative $\mathrm{PL}$ via energy transfer from $\mathrm{ZnO}$ to the complex seems to operate for the $\mathrm{ZnO} /$ hqs- $\mathrm{Al}^{3+}$ hybrid system.

\section{Acknowledgment}

This work was supported by Industrial Technology Research Grant Program (06A22002d) from New Energy and Industrial Technology Development Organization (NEDO) of Japan
5. References

[1] S.V. Gaponenko, "Optical properties of Semiconductor Nanocrystals", Cambridge University Press, Cambridge (1998).

[2] L. Vaysière, K. Keis, A. Hagfeldt and S.E. Lindquist, Chem. Mater., 13, 4395 (2001).

[3] Z.R. Tian, J.A. Voigt, J. Liu, B. Mckenzie, M. J. Mcdermott, M. A. Rodriguez, H. Konishi and H. Xu, Nature Mater., 2, 821 (2003).

[4] T. Yoshida, M. Iwaya, H. Ando, T. Oekermann, K. Nonomura, D. Schlettwein, D. Wöhrle and H. Minoura, Chem. Commun., 400 (2004).

[5] T. Pauporté and D. Lincot, Appl. Phys. Lett. , 75, 3817 (1999).

[6] M. Izaki, S. Watase and H. Takahashi, Adv. Mater., 23, $2000(2003)$

[7] A. Tsukazaki, A. Ohtomo, T. Onuma, M. Ohtani, T. Makino, M. Sumiya, K. Ohtani, S. F.Chichibu, S. Fuke, Y. Segawa, H. Ohno, H. Koinuma and M. Kawasaki, Nature Mater., 4, 42 (2005).

[8] A. Goux, T. Pauporte and D.Lincot, J. Electroanal. Chem., 587, 193 (2006).

[9] K.E. McBean, E. Katie, M.R. Phillips and E.M. Goldys, Microscopy and Microanalysis , 12, 327 (2006). [10] A. Ishizumi and Y. Kanemitsu, Appl. Phys. Lett. 86 $253106(2005)$

[11] J. Kido, K. Nagai, Y. Okamoto, and T. Skotheim, Chem. Lett. 7, 1267 (1991).

[12] J. Kido, K. Nagai, and Y. Ohashi, Chem. Lett. 4, 657 (1990).

[13] T. Pauporté, T. Yoshida, D. Komatsu, H. Minoura, Electrochem. Solid St. 9, H16, (2006).

[14] T. Jin, S. Tsutsumi, Y. Deguchi, K. Machida and G. Adachi, J. Alloys Comp., 252, 59 (1997).

[15]T. Yoshida, M. Tochimoto, D. Schlettwein, D. Woehrle, T. Sugiura and H. Minoura, Chem. Mater., 11, 2657 (1999).

[16]T. Yoshida, K. Terada, D. Schlettwein, T. Oekermann, T.Sugiura and H.Minoura, Adv. Mater, 12, $1214(2000)$

[17] T. Yoshida, T. Oekermann, K. Okabe, D. Schlettwein, K. Funabiki and H. Minoura, Electrochemistry, 70, 470 (2002).

[18] T. Yoshida, T. Pauporté, D. Lincot, T. Oekermann and H. Minoura, J, Electrochem. Soc., 150, C608 (2003).

[19] T. Yoshida, M. Iwaya, H. Ando, T. Oekermann, K. Nonomura, D. Schlettwein, D. Woehrle, H.Minoura, Chem. Comm., 4, 400 (2004).

[20] R.Ballardini, G. Varani, M. T. Indelli and F. Scandola, Inorg. Chem. 25, 3858 (1986).

[21] E. van Veldhoven, H. Zhang and M. Glasbeek, $J$. Phys. Chem. A., 105, 1687 (2001).

[22] P. E. Burrows, Z. Shen, V. Bulovic, D. M. McCarty, S.R. Forrest, J. A. Cronin and M. E. Thompson, J. Appl. Phys., 79, 7991 (1996).

[23] R. Katoh, A. Furube , A.V. Barzykin , H. Arakawa and M. Tachiya, Coord. Chem. Rev. 248, 1195 (2004).

[24] A. Yamamoto, Y. Kikuchi, A. Ishizumi, H. Yanagi, H. Iwai and T. Yoshida, Jpn. J. Appl. Phys., 47, 625 (2008).

(Received December 30, 2007;Accepted Febrary 12, 2008) 